\title{
Configurações
}

Revista de sociologia

\section{Memórias amnésicas? Nação, discurso político e representações do passado colonial*}

Amnesic Memories? Nation, political discourse and representations of the colonial past

Mémoires amnésiques? Nation, discours politique et représentations du passé coloniale

\section{Miguel Cardina}

\section{(2) OpenEdition}

\section{Journals}

Edição electrónica

URL: http://journals.openedition.org/configuracoes/3281

DOI: $10.4000 /$ configuracoes.3281

ISSN: 2182-7419

\section{Editora}

Centro de Investigação em Ciências Sociais

\section{Edição impressa}

Data de publição: 27 Junho 2016

Paginação: 31-42

ISSN: 1646-5075

Refêrencia eletrónica

Miguel Cardina, « Memórias amnésicas? Nação, discurso político e representações do passado colonial* », Configurações [Online], 17 | 2016, posto online no dia 30 junho 2016, consultado o 02 maio 2019. URL : http://journals.openedition.org/configuracoes/3281; DOI : 10.4000/configuracoes.3281 
Cardina, Miguel - Memórias amnésicas? Nação, discurso político e representações do passado colonial Configurações, vol. 17, 2016, pp. 31-42

\title{
Memórias amnésicas? Nação, discurso político e representações do passado colonial*
}

\author{
MIGUEL CARDINA**
}

CES, Universidade de Coimbra

\section{Resumo}

$\mathrm{O}$ artigo toma como base empírica um conjunto de discursos proferidos recentemente em momentos comemorativos pelo Presidente da República Portuguesa, Aníbal Cavaco Silva. Analisam-se as imagens do passado colonial aí presentes e de que forma elas se conectam com uma certa "memória amnésica" que valoriza a nação a partir da singularidade das "Descobertas", da especificidade da presença portuguesa no mundo e dos legados de fraternidade deixados nas antigas colónias. Deste modo, procura-se contribuir para a reflexão sobre o papel do discurso e da autoridade política na difusão de representações seletivas do passado e sobre as dinâmicas entre memória, poder e silenciamentos.

Palavras-chave: memória, nação, passado colonial, poder.

\begin{abstract}
Amnesic Memories? Nation, political discourse and representations of the colonial past This article explores a set of recent speeches delivered at commemorative events by the President of the Portuguese Republic, Aníbal Cavaco Silva. Images of the colonial past are analyzed, showing how they are connected with a certain "amnesic memory" that values the nation from the perspective of the uniqueness of the "Discoveries", the specificity of the Portuguese presence in the world and the legacies left in the former colonies. Thus, it seeks to contribute to an understanding of the role of political discourse and political authority in the dissemination of selective representations of the past, as well as to offer a reflection on the dynamics among memory, power and silencing.
\end{abstract}

Keywords: memory, nation, colonial past, power.

\footnotetext{
* Este texto foi desenvolvido no âmbito do projeto Echoes: Historicizing Memories of the Colonial War, financiado pela Fundação para a Ciência e a Tecnologia (IF/00757/2013). Uma versão prévia foi apresentada no IX Congresso Ibérico de Estudos Africanos, decorrido em Coimbra, a 11 de setembro de 2014.

** Investigador no Centro de Estudos Sociais, Universidade de Coimbra. Email: miguelcardina@ces.uc.pt.
} 


\begin{abstract}
Résumé
Mémoires amnésiques? Nation, discours politique et représentations du passé coloniale Cet article prend comme base empirique un ensemble de discours dans les moments de célébration, faites récemment par le Président de la République Portugaise, Aníbal Cavaco Silva. Les images du passé coloniale sont analysées, montrant comment ils se connectent avec une certaine «mémoire amnésique» qui valorise la nation des «découvertes», la spécificité de la présence portugaise dans le monde et l'héritage laissé dans les anciennes colonies. Ainsi, il vise à contribuer à l'examen du rôle du discours politique et l'autorité politique dans la diffusion de représentations sélective du passé et à la réflexion sur la dynamique entre mémoire, pouvoir et silences.
\end{abstract}

Mots-clés: mémoire, nation, passé coloniale, pouvoir.

\title{
Introdução
}

O presente artigo faz parte de uma reflexão sobre o conteúdo e a forma como em Portugal se têm construído imagens do colonial que, ao mesmo tempo que enaltecem a nação a partir da singularidade das "Descobertas" e da especificidade da "presença portuguesa no mundo", produzem reconfigurações semânticas e desvios interpretativos que rasuram a natureza do colonial como colonial. Tomando como objeto de análise um conjunto de discursos proferidos entre 2006 e 2014 por Aníbal Cavaco Silva, então Presidente da República Portuguesa, procura-se observar de que modo aquelas representações têm persistido no período democrático e pós-imperial. Em sentido mais amplo, o texto visa contribuir para a reflexão sobre o papel da autoridade política na difusão de certas representações seletivas do passado e para a problematização das dinâmicas entre memória, poder e silenciamentos.

\section{Memória, poder e silenciamentos}

Importa notar que a reflexão sobre a natureza da memória social e sobre os seus usos políticos ganhou, nas últimas décadas, um lugar crescente nos centros de produção intelectual. É verdade que os trabalhos pioneiros de Maurice Halbwachs, na primeira metade do século XX, haviam aberto já o caminho para a reflexão sobre a "memória coletiva" e o modo como ela é produzida na interação social (Halbwachs, 1994; 1997). Todavia - e como assinalou o historiador Enzo Traverso - nas décadas de 1960 e 1970 o conceito estava ainda longe de possuir a relevância que veio posteriormente a adquirir no campo das ciências sociais e das humanidades (Traverso, 2007).

Foi sobretudo a partir de meados da década de 1980 que o campo interdisciplinar dos "estudos da memória" se viria a consolidar, quer por via da reflexão sobre o fenómeno do Holocausto e das “memórias traumáticas”, quer pela atenção dada à relação entre identidade nacional e materializações da 
memória, sedimentada numa série de trabalhos que seguiram no encalço de conceitos como o de "lugares de memória", inicialmente avançado por Pierre Nora $(1984 ; 1986 ; 1992)$. Ao mesmo tempo, os impactos do cultural turn na reflexão historiográfica complexificaram as relações entre história e memória e transformaram esta última, não só em fonte histórica, mas também em objeto de estudo ${ }^{1}$. A emergência do que alguns consideram um verdadeiro "boom da memória" deu-se assim num quadro marcado por processos de (re)construção nacional, por uma maior sensibilidade relativamente aos legados de guerras, genocídios e crimes contra a humanidade e, por fim, pelas mudanças tecnológicas que permitiram uma crescente e mais plural difusão de leituras do passado.

Se é certo que a memória das vítimas, particularmente as que resultaram do Holocausto, concitou uma particular atenção num primeiro momento, os estudos da memória ampliaram posteriormente os seus temas e assistiu-se à proliferação de novas ferramentas conceptuais. Michael Rothberg avançou com a proposta de se ativar uma "memória multidirecional" que articule diferentes passados (por exemplo, a memória do Holocausto e a memória da escravatura e do colonialismo) a partir de uma perspetiva "não competitiva", ou seja, que resista ao ímpeto de considerar as diferentes memórias num espaço público onde a sua possibilidade de inscrição seria escassa e, portanto, sempre determinada por uma lógica concorrencial. A noção de "memória multidirecional” permitiria assim colocar em contraste produtivo diferentes memórias com aspetos comuns, abrindo espaço para o diálogo e para a visibilização de experiências, processos e acontecimentos rasurados da memória pública (Rothberg, 2009).

Essa proposta deverá ter em conta, todavia, que o reconhecimento dos passados - e sobretudos dos passados de injustiça e sofrimento - depende do poder que os grupos sociais têm ou não para inscrever socialmente as suas narrativas e para desafiar as representações dominantes na sociedade. Com efeito, memória e esquecimento/silenciamento são construções forjadas na relação dialética com a ordem social e política vigente. Nesta medida, poder-se-ia mesmo dizer que todos os Estados, nações e comunidades possuem "políticas de memória”, ou seja, mecanismos através dos quais se selecionam marcos históricos e se constituem narrativas, instituições e valorações que as dotam de conteúdo e sentido. E que as "políticas da memória", assim entendidas, não são indissociáveis das "políticas de silêncio", através das quais se constroem e ativam versões seletivas do ocorrido.

$\mathrm{Na}$ verdade, o silêncio não é um espaço em branco à espera de ser preenchido mas antes um "espaço socialmente construído no qual, e sobre o qual, sujeitos e palavras (...) não se expressam” (Winter, 2010: 4). Michel-Rolph

1 Essa dupla condição está bem patente nas transformações operadas na história oral justamente a partir de meados da década de 1980, transformando-se esta não apenas numa prática associada ao uso de testemunhos orais mas também num campo problematizador do tema da memória. Veja-se Cardina (2012), Portelli (2013) e Abrams (2014). 
Trouillot mostrou de que forma o silêncio é inerente à produção historiográfica, manifestando-se no momento da criação das fontes, no processo de constituição de arquivos e na construção posterior de narrativas e significados históricos sobre os eventos (Trouillot, 1995: 26). Neste sentido, o silêncio pode resultar da incapacidade dos indivíduos gravarem a sua narrativa no espaço público (devido à proximidade temporal do evento, ao desconforto social causado pela narrativa, ou à falta de mecanismos sociais e discursivos para a tornar “audível”). Mas também, adicionalmente, como expressão de uma ordem hegemónica que oblitera determinadas experiências vividas, memórias partilhadas ou análises do passado.

Isso é válido também para a relação entre passado, poder e nação. Como nota Prasenjit Duara, a imagem das nações como sujeitos da história repousa numa certa ideia de intemporalidade: é pensando-as como unidades homogéneas, mais ou menos imperturbáveis à passagem do tempo, que as nações se postulam como entidades duradouras (Duara, 1998). Enquanto "comunidade imaginada" (Anderson, 1983), as nações alimentam-se de um feixe de representações e interpretações sobre o seu passado. Sedimentadas em diferentes escalas $^{2}$, essas imagens têm uma articulação particularmente poderosa e eficaz nas instâncias relacionadas com o Estado ou na produção discursiva dos seus representantes máximos.

\section{Cinco tópicos}

Efetivamente, a natureza dos discursos políticos passa mais pela reiteração de momentos simbólicos ou de narrativas fundacionais do que pela elaboração de argumentos historiográficos (Shenhav, 2008). O presente artigo observa-o partindo dos discursos proferidos, entre 2006 e 2014, pelo Presidente da República Portuguesa, Aníbal Cavaco Silva³, nas sessões solenes comemora-

2 Abordando o estudo das memórias de guerra no século XX, Timothy Ashplant, Graham Dawson e Michael Roper propõem uma "abordagem integrada", que considere a diferentes níveis, e de acordo com os diferentes casos, o papel e as articulações existentes entre indivíduos, sociedade civil e Estado na produção das memórias políticas. Cf. Ashplant, Dawson e Roper (2000).

3 Desde meados da década de 1980 que a figura de Aníbal Cavaco Silva se tornou central na história política portuguesa. Nascido em 1939 em Boliqueime, no Algarve, vem para Lisboa estudar em meados da década de 1950 e, entre 1962 e 1965, cumprirá o serviço militar, permanecendo em Lourenço Marques (atual Maputo). Inicia de seguida uma carreira como economista e académico. Em 1980 torna-se ministro das Finanças da Aliança Democrática (coligação de direita que englobava o Partido Social Democrata, o Centro Democrático Social e o Partido Popular Monárquico). Em Julho de 1985 chega à liderança do PSD e, pouco depois, torna-se Primeiro-Ministro, cargo que ocupará até 1995. É o período da adesão de Portugal à então Comunidade Económica Europeia, de um conjunto de reformas liberalizadoras e, na sua fase final, de incremento da contestação social ao "cavaquismo". Após ter sido derrotado por Jorge Sampaio nas Presidenciais de 1996, Cavaco Silva candidata-se novamente em 2006, vencendo a contenda e permanecendo até 2016 em Belém. Apesar da sua proeminência no cenário político português nas últimas décadas, manteve quase sempre uma pose e um discurso na qual se autorrepresentava como "não-político", numa mobilização simultânea das figuras do "self made man", do "professor de Economia" e do "governante por obrigação moral". 
tivas do 25 de Abril e do 10 de Junho. A primeira data evoca, como é sabido, o dia em que o Movimento das Forças Armadas (MFA) produziu o golpe que derrubou o Estado Novo. Desafiando a imagem de um povo resignado e de "brandos costumes", durante o chamado "biénio revolucionário" (1974-1976) abalou-se o aparelho repressivo proveniente da ditadura, questionou-se a estrutura da propriedade, ensaiaram-se novas formas de organização e expressão da vontade popular, conquistaram-se liberdades públicas e assistiram-se a processos de independência de antigas colónias africanas. Pela sua centralidade, o 25 de Abril tem sido um termómetro particularmente sensível às mutações que o país foi sofrendo nas últimas quatro décadas, sendo alvo de múltiplas, conflituantes e por vezes truncadas evocações (Loff, 2014).

As comemorações do 10 de Junho, por sua vez, têm uma história mais antiga: as suas origens remontam às celebrações republicanas do tricentenário de Camões, em 1880, e o dia seria depois transformado pela República em feriado municipal de Lisboa. Em 1933, com o advento do Estado Novo, viria a ser nomeado como "Dia da Raça”, e recriado a partir de 1963 num aparatoso momento de glorificação pública do esforço de guerra conduzida em África. Com a queda da ditadura, a celebração seria interrompida. A data voltaria a ser festejada, agora renomeada como "Dia de Portugal, de Camões e das Comunidades Portuguesas", a partir de 1977, decorrendo anualmente a cerimónia numa diferente cidade do país.

Enaltecendo o regime político e a Nação, ambos os feriados condensam momentos retóricos que manejam e deixam sugeridas certas interpretações da história nacional. Ao serem articulados pela instituição máxima da República, estes quadros históricos adquirem evidentemente um maior alcance político e simbólico. Pela sua natureza, estes são momentos performativos nos quais se pretende interferir no real político. Não são pois imunes às circunstâncias sociopolíticas em que ocorrem e às quais os discursos aludem. Cabe frisar, porém, que se é verdade que os discursos a observar não têm a reflexão sobre a história como objeto primordial, apesar disso se tece aí um vínculo entre contextos do passado e um presente político na qual a voz do Presidente busca reverberar e provocar efeito.

A análise dos dezasseis discursos em questão - oito proferidos no 25 de Abril, oito proferidos no 10 de Junho - permite identificar a presença de cinco tópicos fundamentais associados à temática colonial. O primeiro tópico reside na imaginação da colonização como tendo consistido essencialmente num "encontro de culturas”. No discurso de 10 de Junho de 2008, afirma Cavaco Silva:

Portugal não se limitou a andar pelo mundo e a conhecer vagamente outros povos com quem se defrontou ou negociou. Portugal entendeu-se e misturou-se realmente com os outros, criou raízes fora de casa, lançou as bases para novas nações e pontes para o diálogo internacional que hoje tanto reivindicamos. 
Este breve excerto condensa três ideias fortes que parecem sugerir a benignidade do colonialismo português relativamente a outros colonialismos. Em primeiro lugar, vinca-se a diferença do seu cosmopolitismo ("não se limitou a andar pelo mundo" mas efetivamente "criou raízes fora de casa"). Em segundo lugar, define-se a relação histórica entre os portugueses e os povos colonizados à luz das noções de convívio e miscigenação ("Portugal entendeu-se e misturou-se realmente com os outros”). Por fim, indica-se, de forma algo imprecisa, que “as novas nações” resultaram das "bases" lançadas pelos portugueses. Trata-se, com efeito, de uma rasura do processo anticolonial que esteve na génese das nações africanas e de uma reconfiguração dos traços fundamentais do luso-tropicalismo, aspeto ao qual se voltará adiante.

O segundo tópico presente reside na evocação do excecionalismo da presença portuguesa no mundo. Essa inscrição específica na História seria produto do que, no mesmo discurso a 10 de Junho de 2008, se define como "universalismo português". É esse impulso que originou a "aventura que lançou os alicerces do mundo tal como ele se apresenta em nossos dias"4. O universalismo luso teria assim dado lugar a uma presença no mundo, não apenas singular, mas ainda hoje culturalmente viva, politicamente frutuosa e socialmente estimada nos territórios outrora sob administração portuguesa. Um sintoma evidente da adoção desta chave de leitura está, não só nas palavras que se escolhem dizer, mas também nas que estão omissas. Com efeito, termos como "colonialismo", "colonização", "racismo" ou "escravatura” não surgem grafados nos dezasseis discursos analisados.

Articulado com o segundo tópico, uma terceira linha de força baseia-se na identificação da língua, da cultura e do património como os produtos históricos daquela "vivência universalista" dos portugueses. O espaço da "lusofonia" aparece sugerido como a reconfiguração contemporânea de um lastro histórico de encontros com outros povos. Conceito ambíguo e complexo (Sousa, 2013), amplificada no quadro da construção da CPLP (Comunidade de Países de Língua Portuguesa), a eficácia da noção estaria - como salienta Michel Cahen - na ressonância que estabelece com um "imaginário colonial duradouro" que contribui para apagar "em uma única palavra realidades sociais extremamente diferentes e status sociais incomparáveis", revelando assim o lastro ainda operativo de um imaginário "sem o colonialismo como política" mas com a colonização enquanto fenómeno sociocultural persistente (Cahen, 2010).

Curiosamente, a palavra "lusofonia" surge apenas uma única vez, no discurso proferido a 25 de Abril de 2014. Isso não significa, porém, que se abdique de postular a existência de um espaço cultural comum a ex-colonizador e

4 Discurso do 10 de Junho de 2007. Aí se acrescenta: “a obra que os Portugueses realizaram não desapareceu, nem ficou perdida no tempo. Longe de ser apenas uma recordação nostálgica, essa obra permanece viva, quer em cada uma das muitas paragens onde constituímos comunidades, quer nessa rede global de contactos em que o planeta está hoje transformado.” 
ex-colonizados, tecido através da língua. A palavra "língua", com efeito, surge com muito mais frequência - quinze vezes nos discursos do 10 de Junho; sete vezes nos discursos do 25 de Abril - funcionando como o elemento que permite referenciar a existência de uma História partilhada. Como é dito a 10 de Junho de 2008, "o facto de nos entendermos na mesma língua e de partilharmos uma História que foi comum durante alguns séculos não é irrelevante”. Frequentes são também as alusões ao valor artístico do património edificado e ao Mar, entendido simultaneamente como veículo central da grandeza passada e horizonte potenciador de um novo desenvolvimento para o país ${ }^{5}$.

Um quarto tópico consiste em definir como europeu o Portugal que então empreendeu a aventura colonial. Como é dito em 2007, "foi Portugal quem primeiro levou a Europa ao encontro de outros povos, tornando assim real e concreto o universalismo que é timbre dos valores europeus". Na verdade, o feixe de palavras mais mencionadas nestes discursos são "Portugal" - "portugueses" - "portuguesas” - “português” (cerca de 400 vezes), logo seguido de "Europa” - "Europeu” - "Europeia” (cerca de 100 vezes). São várias as expressões que põem como ator da aventura colonial um "Portugal europeu" e, consequentemente, uma Europa entendida como farol do mundo. Em 2007, considera-se que Portugal foi "o rosto visível da civilização europeia nos quatro cantos do mundo". Em 2010 afirma-se que "difundimos por toda a parte a cultura de um continente ancestral, que durante muitos séculos vivera voltado sobre si mesmo".

A maioria das referências faz eco obviamente da atualidade política e da relevância da União Europeia na definição dos destinos do país, e que seria, como é sabido, acentuada com o incremento da dependência político-económica a seguir ao resgate da troika, em 2011. Com esse pano de fundo, as referências de teor histórico tendem a procurar demostrar o carácter ancestralmente europeu do país, tomando como natural a pertença, não só ao continente, como ao "projeto europeu". Ao mesmo tempo, buscam vincar uma especificidade cujo traço essencial, neste caso, estaria no espírito pioneiro com que "revelámos à Europa dois terços do planeta" (25/04/2010). Neste sentido, estes discursos revelam a vontade de combinar aquilo que Rita Ribeiro designou os dois polos fundamentais através dos quais se foi pensando a identidade nacional: a “vocação atlântica” e a “opção europeia” (Ribeiro, 2011: 93).

\footnotetext{
5 Na verdade, o Mar e a sua relação com a história do país tem lugar em praticamente todos os discursos do 10 de Junho. No Porto, em 2006, fala-se da "insatisfação colectiva que nos levou por mares tão longínquos”. Em 2007, em Setúbal, menciona-se o facto de "conhecermos o mar como ninguém”. Em 2008, em Viana do Castelo, evoca-se o "povo que se fez ao mar". Em 2009, em Santarém, refere-se a "aventura marítima”. Em 2012, em Lisboa, recordam-se as "grandes epopeias náuticas de Quinhentos”. O Mar sinaliza uma espécie de novo desígnio nacional que faria ecoar a ancestral simbiose com esse elemento: daí as referências ao "cluster do mar", à "aposta portuguesa no mar" e à "economia do mar" (2007). Esta leitura está em linha, aliás, com iniciativas como a campanha governamental "Portugal é Mar", lançada em 2014, e que teve uma das suas facetas na obrigatoriedade de afixação nas escolas de um mapa em que se mostrava um país que não era pequeno, se consideradas as suas adjacências marítimas.
} 
Por fim, um quinto e último tópico remete para o silêncio sobre a guerra colonial - que é, no fundo, um silêncio sobre as razões do fim do Império e os antecedentes do 25 de Abril. Quando tem necessidade de mencionar o tema como aconteceu em 2011 na "Cerimónia de Homenagem aos Combatentes da Guerra em África" - Cavaco Silva usa as expressões "Guerra em África” ou mesmo "Guerra do Ultramar", a designação usada pelo Estado Novo para indicar a guerra que decorria - não nas “colónias”, que o regime considerava não ter - mas nas "províncias ultramarinas"7. Efetivamente, a expressão "guerra colonial” não surge nos discursos observados, e o próprio termo "guerra”, sem outro qualificativo apenso, aparece uma única vez, no discurso de 25 de Abril de 2010, fazendo-se aí menção abstrata a um tempo histórico em que "caía um regime cansado de guerra".

A queda do regime é assim interpretada essencialmente à luz dos direitos cívicos coartados e da evocação da ação do MFA, omitindo-se o papel da guerra colonial na gestação do movimento e o lugar dos movimentos de libertação africanos no desgaste decisivo da ditadura. Desta forma, a leitura do 25 de Abril veiculada por Cavaco Silva é composta por dois cortes: um primeiro corte, entre o "regime autoritário" (expressão usada quatro vezes, em detrimento de Estado Novo ou "fascismo") e a democracia; e um segundo corte, entre a democracia e as ameaças à sua consolidação, identificadas nas movimentações políticas e sociais empreendidas nos momentos mais quentes da revolução. Desta forma, rasura-se a importância do processo revolucionário, entendendo-se a consolidação da democracia como resultado da derrota da revolução e não como um produto histórico originado por um compromisso em que se conteve a revolução mas dela se recolheram traços e conquistas substanciais (Rosas, 2014). ${ }^{8}$

\section{Um neo-luso-tropicalismo?}

Estes cinco tópicos apontam para a persistência de um imaginário de traços coloniais, de timbre luso-tropicalizante9, num espaço-tempo pós-colonial. Nestes discursos, a questão colonial é pois deslocada através de um mecanismo

6 Silva (2011/2012: 49-51). Nos discursos militares do 10 de Junho, a menção à guerra colonial aparece por duas vezes, sempre designada como "guerra em África".

7 Expressão introduzida com a revisão constitucional de 1951, e suscitada pelos ventos descolonizadores provenientes do pós 2 . $^{\mathrm{a}}$ guerra mundial.

8 Essa valorização da democracia apesar do processo revolucionário está presente em excertos como este: "Em 1974, foi necessário fazer uma revolução para mudar de regime. Mas, depois, foi necessário construir um regime novo, um regime democrático. (...) O regime democrático encontra-se atualmente consolidado porque o bom senso prevaleceu sobre o aventureirismo, porque o sentido de responsabilidade foi mais forte que as tentações extremistas." (25 de Abril de 2012).

9 Elaborado por Gilberto Freyre, o luso-tropicalismo teve, como é sabido, receção significativa em Portugal, sobretudo a partir de meados da década de 1950, quando veio substituir as teses de matriz mais claramente racistas, usadas para sustentar a legitimidade do que, do Acto Colonial de 1930 em diante, vinha sendo designado como "Império Colonial Português" (Castelo, 1999). Apontando a capacidade inata dos portugueses em se miscigenar e interpenetrar culturalmente, o luso-tropicalismo teve incorporação nas elites do regime mas também expressão visível diversificada na cultura de massas 
que omite os processos históricos ligados ao racismo, à escravatura e à dominação económica e cultural e que, em alternativa, realça o papel da língua, do património e do Mar como componentes diferenciadoras da experiência colonial portuguesa. Assim se reciclam, deste modo, um conjunto de tópicos sobre os "Descobrimentos" e a singularidade do "modo português de estar no mundo" (Castelo, 1999), com recurso a uma nova linguagem e conferindo primazia a aspetos como a tónica na ideia de um "Portugal europeu" como agente do processo de expansão colonial. Se estas interpretações revelam uma dada leitura da História - e dos seus usos no presente - elas dão conta também da dificuldade em evocar a dimensão violenta do colonialismo e a forma traumática como se encerrou o ciclo do Império ${ }^{10}$.

Miguel Vale de Almeida usa o conceito de "luso-tropicalismo genérico" para identificar a presença reconfigurada desse imaginário de miscigenação e tolerância no contexto pós-ditatorial, sob a égide contemporânea da "lusofonia", e num quadro em que este mencionado "luso-tropicalismo genérico" revela permanências múltiplas, "como inclinação, como interpretação de senso comum e por vezes como representação oficial" ". Como nos recorda Eduardo Lourenço, Portugal é o lugar "da mais espectacular boa consciência colonial que a História regista", baseado no esquecimento ativo de que "o seu império era fruto da colonização, isto é, do encontro com outrem sob uma forma que não exclui, nem excluiu, a violência” (Lourenço, 2014: 137). A natureza do colonialismo como "nosso impensado" repousaria justamente na incapacidade para se assumir a sua natureza histórica do colonialismo e os legados que ele deixou após se ter dissipado como realidade política.

De acordo com Manuel Loff, num estudo sobre a memória da ditadura e da revolução no Portugal democrático, as últimas décadas assistiram em Portugal à consolidação de leituras sobre o colonialismo e a guerra colonial simultaneamente antagónicas e comunicantes. Por um lado, manteve-se no essencial a perceção de que o 25 de Abril de 1974 consistira numa rutura socialmente benéfica para a larga maioria da população, o que colocava a ditadura e a guerra como uma espécie de contraponto negativo que a Revolução dos Cravos havia suplantado. Por outro lado, uma certa memória valorizadora da "África perdida", articulada com a ideia de uma descolonização atabalhoada e profundamente lesiva,

durante os anos finais da ditadura (Cardão, 2015), o que na verdade ajudará a explicar a presença desses postulados no Portugal democrático e pós-imperial.

10 Em 2008, numa visita oficial a Moçambique, perguntado sobre se não teria chegado a hora de Portugal reconhecer publicamente a existência de massacres como o de Wiriamu e de pedir desculpas por isso, Aníbal Cavaco Silva respondeu afirmando que não se deve "ficar sempre a olhar para o passado”. Ana Sá Lopes (2008), “O antigo alferes não pede desculpas por Wiriamu”, Diário de Notícias, 25 de Março de 2008.

11 Almeida (2000: 182). Vale de Almeida nota que o luso-tropicalismo "ganhou o estatuto de facto social cujos contornos deveriam ser estudados", o que implicaria considerar "certas factualidades históricas e sociais que estiveram na origem do luso-tropicalismo" mas também analisar criticamente os processos que lhe conferem resiliência e lhe permitem manter-se operativo. 
criou o pano de fundo para a proliferação de imagens nostálgicas que tendem a omitir o papel da violência colonial. Como refere a este respeito, "ao mesmo tempo que se percebera que a guerra fora um instrumento inaceitável de bloqueio do direito à autodeterminação dos africanos, uma parte provavelmente maioritária da sociedade não achava, como parece ainda hoje ser o caso, que a dominação colonial fora igualmente inaceitável” (Loff, 2014: 56).

Luciana de Castro Soutelo descortinou o reforço de uma leitura política conservadora relativamente ao 25 de Abril à memória do antifascismo em meados da década de 1980, matizando-se crescentemente a valorização do 25 de Abril com a observação do período revolucionário como tendo sido uma espécie de 'desvario' corrigido pelo 25 de Novembro de 1975 (Soutelo, 2009). Em sentido semelhante, Carlos Maurício examinou sondagens de opinião, publicadas entre 1973 e 2004, a partir das quais seria possível cotejar a evolução da opinião pública relativamente à guerra, ao Império e à descolonização. Faz notar que "após um período de relativa amnésia e de recusa de debate público, o 20. ${ }^{\circ}$ aniversário do 25 de Abril permitiu uma alteração no modo como a opinião pública encarava a guerra colonial e a descolonização", com a expressão crescente de uma "visão revisionista do colonialismo e muito crítica da descolonização” (Maurício, 2011: 291).

Estas perceções têm nas instâncias políticas, nos média, mas também na escola espaços particularmente significativos de articulação. Analisando as representações do processo colonial entre estudantes portugueses e moçambicanos, Rosa Cabecinhas e João Feijó notaram divergências entre os dois grupos. Se os estudantes portugueses tenderam a focar nos "Descobrimentos" e na narrativa do "encontro cultural", os estudantes moçambicanos destacaram mais a conquista de independência e os efeitos nefastos da colonização (Cabecinhas e Feijó, 2013). Como também foi demonstrado recentemente, os manuais escolares em Portugal comportam ainda modos eurocêntricos de pensar o passado colonial, que resultam numa naturalização do colonialismo e numa "presença ausente do racial", ou seja, numa despolitização do racismo na contemporaneidade (Araújo e Maeso, 2013). Estes exemplos ajudam a perceber a eficácia política de um colonialismo ilibado da sua natureza e estatuto.

\section{Nota conclusiva}

O discurso governativo e institucional é modelado em função das convicções, dos contextos e da personalidade dos atores envolvidos. Bastará pensar-se na diferença entre Aníbal Cavaco Silva e dois outros ocupantes do cargo (Mário Soares e Jorge Sampaio) ou até com o atual inquilino de Belém, Marcelo Rebelo de Sousa, oriundo da sua área política, para que esta sugestão ganhe alguma evidência. No entanto, importaria perceber em que medida certos tópicos, como os que este artigo explora, são alvo de representações substancialmente 
diferenciadas ou apenas objeto de modelações retórico-discursivas nos diferentes ocupantes do cargo. Deixaremos para uma ocasião futura essa análise diacrónica dos discursos presidenciais.

No caso em apreço, tomou-se como hipótese que as narrativas sobre o colonial expressas por Aníbal Cavaco Silva, estando em linha com o pensamento do cidadão que as profere e resultando de estratégias própria do discurso político, podem igualmente ser tomadas como uma espécie de memória pública dominante, justamente porque a sua eficácia assenta na perceção de que essas versões sobre a nação e sobre os legados coloniais fazem parte de um senso comum enraizado. Ou seja, de um conjunto de considerações sobre o passado do qual faz parte a ideia da singularidade da experiência colonial portuguesa e do lastro histórico que deixou. Desta forma se tem contribuído para promover a ideia de um colonial extirpado da sua dimensão histórica de dominação. Ao mesmo tempo, e situado na periferia de uma União Europeia em crise, nestes discursos o estatuto europeu do país é aditivado a partir de um passado imperial que se dá a ver como parte da sua identidade. E, como nos diz Boaventura de Sousa Santos, "destinos nacionais" e "horóscopos coletivos" são sempre "expressão de um défice de presente que projeta num futuro excessivo o excesso de passado" (Santos, 1996: 65).

\section{Referências}

ABRAMS, Lynn (2014), "Memory as both source and subject of study", in Stefan Berger e Bill Niven (ed.), Writing the History of Memory. Londres: Bloomsbury, 89-109.

ANDERSON, Benedict (1983), Imagined Communities: Reflections on the Origin and Spread of Nationalism. Londres: Verso.

ARAÚJO, Marta; MAESO, Silvia Rodríguez (2013), "A presença ausente do racial: discursos políticos e pedagógicos sobre História, "Portugal” e (pós-)colonialismo". Educar em Revista, 47: $145-171$.

ASHPLANT, Timothy; DAWSON, Graham; ROPER, Michael (org.) (2000), Commemorating War: The Politics of Memory. New York: Routledge.

DUARA, Prasenjit (1998), "The Regime of Authenticity: Timelessness, Gender, and National History in Modern China". History and Theory, 37 (3): 287-308.

CABECINHAS, Rosa e FEIJÓ, João (2013), "Representações sociais do processo colonial - perspetivas cruzadas entre estudantes moçambicanos e portugueses". Configurações, 12: 117-139.

CAHEN, Michel (2010), "Lusitanidade e lusofonia. Considerações conceituais sobre realidades sociais e políticas". Plural Pluriel. Revue des Cultures de langue portugaise, 7 (online): URL: www.pluralpluriel.org.

CARDINA, Miguel (2012), "História Oral - caminhos, problemas e potencialidades", in Paula Godinho (org.), Usos da Memória e Práticas do Património. Lisboa: Colibri, 27-43.

CARDÃO, Marcos (2015), "Allegories of exceptionalism: Lusotropicalism in mass culture (1960-74)". Portuguese Journal of Social Sciences, 14 (3): 257-273.

CASTELO, Cláudia (1999), O modo português de estar no mundo. O luso-tropicalismo e a ideologia colonial portuguesa (1933-1961). Porto: Afrontamento.

HALBWACHS, Maurice (1994) Les cadres sociaux de la mémoire. Paris: Albin Michel [1. ${ }^{a}$ ed. 1925]. 
HALBWACHS, Maurice (1997), La mémoire collective. Paris: Albin Michel [1. a ed. 1950].

LOFF, Manuel (2014), "Estado, democracia e memória: políticas públicas e batalhas pela memória da ditadura portuguesa (1974-2014)”, in Manuel Loff, Luciana Soutelo (retirar vírgula) e Filipe Piedade (Coord.), Ditaduras e Revolução. Democracia e Políticas da Memória. Coimbra: Almedina, 23-144.

LOURENÇO, Eduardo (2014), O colonialismo como nosso impensado. Organização e prefácio de Margarida Calafate Ribeiro e Roberto Vecchi. Lisboa, Gradiva, 149-170.

MAURÍCIO, Carlos (2011), “A Guerra Colonial e a Descolonização vistas pelas Sondagens de Opinião (1973-2004)”. Nação e Defesa, 130: 267-295.

NORA, Pierre (1984-1986-1992), Les lieux de mémoire. Paris: Gallimard. 3 vols.

PORTELLI, Alessandro (2013), A morte de Luigi Trastulli e outros ensaios. Organização de Miguel Cardina e Bruno Cordovil. Lisboa: UNIPOP.

RIBEIRO, Rita (2011), "A Europa em Portugal: uma cartografia das distâncias”, in Maria de Fátima Amante (coord.), Identidade Nacional entre o Discurso e a Prática. Porto: CEPESE / Fronteira do Caos, 91-102.

ROTHBERG, Michael (2009), Multidirectional Memory. Remembering the Holocaust in the Age of Decolonization. Stanford: Stanford University Press.

SANTOS, Boaventura de Sousa (1996), "Onze Teses por Ocasião de mais uma Descoberta de Portugal”, in Pela Mão de Alice. O Social e o Político na Pós-Modernidade. Porto: Afrontamento, 49-67, 6. a edição.

SHENHAV, Shaul R. (2008), "Showing and telling in parliamentary discourse: the case of repeated interjections to rabin's speeches in Israeli parliament”. Discourse and Society, 19: 23-255.

SILVA, Aníbal Cavaco (2011/2012), Roteiros VI. Lisboa: Imprensa Nacional - Casa da Moeda.

SILVA, Aníbal Cavaco, Discursos proferidos entre 2006 e 2015 nas sessões solenes do 25 de Abril e nas comemorações civis do 10 de Junho. Consultados na página oficial da Presidência da República: http://www.presidencia.pt/

SOUSA, Victor de (2013), "O difícil percurso da lusofonia pelos trilhos da 'portugalidade"”. Configurações, n. ${ }^{\circ}$ 12: 89-104.

SOUTELO, Luciana de Castro (2009), A Memória do 25 de Abril nos Anos do Cavaquismo: o desenvolvimento do revisionismo histórico através da imprensa (1985-1995), dissertação de mestrado, Faculdade de Letras da Universidade do Porto, Porto.

TRAVERSO, Enzo (2007), El pasado, instrucciones de uso. Historia, memoria, politica. Madrid e Barcelona: Marcial Pons.

TROUILlOT, Michel-Rolph (1995), Silencing the Past. Power and the Production of History. Boston: Beacon Press.

WINTER, Jay (2010), 'Thinking about silence', in Efrat Ben-Ze'ev, Ruth Ginio, Jay Winter (org.), Shadows of War. A Social History of Silence in the Twentieth Century. Cambridge: Cambridge University Press, 3-31. 